\title{
Upfront
}

\section{Democratize Foresight and Accelerate Learning: Interview with Olugbenga Adesida}

In this interview by Aidan Eyakuze and Arthur Muliro, Olugbenga Adesida reflects on his experience working with African governments under the umbrella of the now-defunct 'Africa Futures' programme which was established by the World Bank and the UNDP to popularize futures work within African governments. Implementing foresight was not easy given the struggle to capture the attention of decision-makers and the perception that the concept was an external imposition. Nonetheless, the validity of foresight for African governments is more urgent today than ever before. He suggests that African governments need to democratize decision-making and find ways of accelerating system-wide learning.

AE: You have been at the forefront of introducing foresight to more than 20 African countries. What stands out for you personally as the most memorable engagement and outcome?

OA: When I look back now I think most of the programme's impact was mostly a failure because if the goal was to help the continent transform the way they do planning, how they manage their economies, we did not succeed.

AM: What do you think were the objective reasons behind that failure?

OA: Many governments saw a foresight exercise as a typical donor project to help them do something today, rather than as a way of changing the way things are done; that it is not a one-off small venture but that it had to be a sustainable support over a long period of time. We interacted with planners who were used to their straitjacket and we did not have the long-term engagement that was necessary to change how they planned and executed. Secondly for this process to succeed we needed to interact with people who had the power to act, to be engaged, to believe in it, to change and to push people to get things done.

AM: When you're engaged with the ministries of planning, was there not buy-in at the highest level? Were there other bureaucratic constraints?

OA: Yes, there was buy-in that says 'OK. This is a good idea. We are looking for ways to develop our countries, so lets do foresight'. That's the first level buy-in.

The deeper or second level buy-in comes from having an experience with foresight that is akin to an epiphany, being 'born again' and that is difficult. Without it, when the foresight process began to raise issues and to question the 'official' future and provide alternative scenarios, people naturally rejected them and questioned their feasibility. The dismissal by Cote d'Ivoire's leaders of the plausibility of a catastrophic scenario is an example. This was some years before the onset of the country's political crisis that had been anticipated by the foresight exercises. 
Mauritius took a different approach. The planners acknowledged the plausibility of the negative scenarios and took steps to make sure it didn't happen in the country. They chose to realize the positive, optimistic scenario by changing their economic strategies, policies and systems. Having based their economy on sugar cane and moved on to textiles, they understood that competition from China and Vietnam in this sector would be fierce and threaten their economy. The foresight activity we did helped them to rethink economic strategy and to move to services - finance, tourism and IT. The Director of Planning who worked directly with us in the foresight process, went on to become the Minister of Finance and Planning and used the insights generated by the foresight process to drive change across the Mauritian economy. In other countries, we did not have this level of commitment.

AE: Some would argue that the foresight messages are sometimes too negative that they don't want to deal with them or they are too utopian.

OA: I think this is what happened in Zimbabwe. Officials thought the message of one of the plausible scenarios was too dark. They refuted its plausibility, refused to take it to Parliament and even asked us to re-write the scenarios. We declined.

AM: As individuals we are adept at using foresight, but collectively and institutionally we seem to be allergic or impervious to this way of working. Why do you think we are unable to learn from the past and the future?

OA: There are a series of issues that cause this kind of thinking. One is our inability to learn socially. Many African countries are looking for the magic bullet that will and solve all of our problems. However, these change every day.

Second, many African decisions are driven by externally sourced proposals and ideas, and this for me is a critical problem. Africa's policy execution started with doing development planning. When that failed to produce results, focus shifted to implementing painful structural adjustment programmes. As these failed to meet aspirations, emphasis was on reducing poverty on top of which was added the quest for achieving the Millennium Development Goals. Instead of going back to basics, learning what worked and discarding what did not in the previous policies, we seem to be looking for the single solution, or the one way to God, which is not there. For me this is a critical challenge and it is affecting our ability to learn as a community.

Beyond that, and let us be frank about this point, leaders in many of our countries are not really there to govern, or to serve or to support a country to transform itself for the better. They are there to rule. As a former President of Zambia said, 'Power is sweet'. When you have the kind of environment in which leaders do not see themselves as part of a process of building a better country and are instead focused on ruling, it will be difficult to pursue an agenda if change in order to do things better.

AE: Does foresight have an inherent fatal flaw in that it depends so much for its effectiveness on the people at the top? If so, how can one remedy that fatal flaw?

OA: The fatal flaw is there because whether we like it or not the people who are leading the countries wield a lot of power, almost excessive in some cases. The state is how we are organized to make things happen. We need to find a way to democratize in an appropriate manner so that you can have competing power centres. Look at Nigeria where Lagos State is doing really well relative to the other 35 federating states. We need to encourage a similar type of dispersal of power that would be very helpful for foresight and for the development agenda.

Another approach is to ensure that the generation, articulation and consumption of foresight becomes popularized and democratized. People will begin to see that alternative futures are important and hopefully, they will begin to question the official future. People need to dare to speak, dare to act and to mobilize others to push leaders in the right direction.

AM: I would like to go back to your point of learning socially. It seems to me that one of the keys to embedding foresight and making sure that it penetrates the roots is to facilitate social learning. How can we work towards this and what do we need to do differently than what we are doing today?

OA: What we are doing today is good but it is not good enough. We are currently improving the 


\section{Development 56(4): Upfront}

methodology and we are doing better scenarios. But, we have to find a way to democratize this process, engage African journalists in the process. We need to enrol critical leaders from different communities to represent their peoples' interests as part of the process, so that the scenarios are articulated at the municipal, provisional to the state level.

AE: You mentioned that foresight is about mindset change. But it is not just about the mindset change of an individual but that of a society and culture too. Aren't you being naïve to think a mindset change at that scale could even happen within ten years?

OA: The challenge for us is that this change needs to happen fast. We think that Africa is relevant to the world because they (rest of the world) need our resources and that we are the only ones who can supply them. We need to ask ourselves, 'What if they don't need our resources anymore?' We mislead ourselves by assuming that the demand for our resources will continue to exist, and that we have the time to adjust to turbulence. So the issue is that while it might take a long time for such a disruptive global shift to happen, you need to ensure that at least the minds of the leadership who are supposed to be more outward looking and more educated are seeing this shift and similar changes and dynamics much faster.

AE: We have tension therefore between the need for democratizing the foresight process and the time required before it's embedded. At the same time, we need to speed up the rate at which the leadership accomplishes the mindset change. Can this tension, between slow democratization of foresight and fast learning, be resolved?

OA: It is resolvable for those who are interested to do so. We have to decide how best to divide our time and resources between these two groups. Can one dedicate a group to push the leadership a little faster? What SID is doing in East Africa is changing the mindset at a much broader level because you are building scenarios on a national and regional scale and you're engaging the political entities, presenting to them and challenging them to think differently.

AE: How can we make foresight more conducive to the policy system?

OA: It is a difficult process because you have to find ways to infiltrate the system. We need the people who can go in, rise up and reform.

AM: Do you see such people?

OA: There are a few people but they are not enough. And the ones who are there are not too eager to join government because they see it as tainted. I can do what I am doing at Cape Verde because I now work with a leadership of the country that is open to ideas and that wants to train people and move forward. If I go to Nigeria and try to sell foresight to them, first they will suspect that I am just trying to sell some snake oil. Secondly, I will probably have to go through ten assistants to get to the decision-maker such as a Minister. As each assistant delays the process for a month it will take ages to do so, and by the time an audience is granted, the person may have been shuffled out of cabinet!

AE: Are you optimistic about the future of foresight or are you giving up on it?

OA: I'm not giving up on foresight. It is a tool that we all need to think and one that is useful for our daily life. Individuals must become agents of this change. And when they begin to see the utility, not just in their job but in their daily lives, it will begin to make a big difference. 